\title{
AIR FLOW IN SNAKE VENTILATION
}

\author{
BRIAN D. CLARK, CARL GANS and H. I. ROSENBERG ${ }^{1}$ \\ Division of Biological Sciences, University of Michigan, Ann Arbor, Michigan 48109, U.S.A.
}

\begin{abstract}
Ventilation in resting, unrestrained Boa constrictor, Python regius and Thamnophis $s$. sirtalis was monitored using various combinations of a closed Kopfkappe (head chamber), intratracheal pressure catheters, strain gauges around the trunk, and a flow meter connected to one of the nostrils. Records of intratracheal pressure with and without closing the Kopfkappe show that the latter device induces artifacts in the normal ventilatory pattern. Flow meter readings from quiescent snakes indicate that ventilation is biphasic (outflow-inflow-pause) rather than triphasic (outflow-inflow-outflow-pause), while simultancous pressure and strain gauge records are variably tri- or quadriphasic.
\end{abstract}

$\begin{array}{ll}\text { Breathing pattern } & \text { Tracheal pressure } \\ \text { Snakes } & \text { Ventilation }\end{array}$

During the 180-year history of the analysis of reptilian ventilation, the process has been repeatedly referred to either as 'biphasic' (outflow-inflow) or as 'triphasic' (outflow-inflow-outflow) depending upon the investigator and the techniques applied (cf. Gans, 1970; Wood and Lenfant, 1976). Statements regarding triphasic ventilation have furthermore been confused in that some authors ascribed the staging to pressure rather than to flow changes.

A series of recent studies (Gans and Hughes, 1967; Gaunt and Gans, 1969; Gans and Clark, 1976) document that unrestrained and more or less calm turtles and crocodilians ventilate biphasically and often have a prolonged apneustic interval between breaths. A theoretical analysis (Gans, 1970) furthermore supports the concept that selection has had a significant influence on the design of the ventilatory system and that animals appear to minimize ventilatory work by various morphological and behavioral devices. Triphasic flow, involving as it does loss of unutilized

\section{Accepted for publication 19 September 1977.}

1 Work completed while visiting associate professor on leave from the Department of Biology. University of Calgary, Calgary, Alberta, Canada. 
oxygen (by a brief 'third' and exhalatory phase) at the beginning of each interbreath interval, must increase the breathing work to no obvious purpose. However, a recent electromyographical analysis (Rosenberg, 1973) again suggested that garter snakes use a triphasic airflow cycle; this conclusion was based upon the results of experiments in which a Kopfkappe was used.

The present note is based on a repetition of some of Rosenberg's experiments and on their expansion to other species of snakes. It analyzes the results he obtained and amplifies them by direct flow measurements. It documents that a Kopfkappe may have a marked effect on the characteristics of the ventilatory cycle and that pressure measurements may only be used as flow indicators if the state of the glottis is directly monitored.

\section{Materials and methods}

Experiments were run at temperatures between 24 and $25^{\circ} \mathrm{C}$ on two $1 \mathrm{~kg}$ ball pythons (Python regius), one $6 \mathrm{~kg}$ boa constrictor (Boa constrictor) and one $80 \mathrm{~g}$ garter snake (Thamnophis s. sirtalis). The trachea of the three larger snakes was intubated through its wall with catheters (PE 60 to 160 polyethylene tubing) inserted as described in Gans and Clark (1976). A closeable Kopfkappe (head chamber or rebreathing chamber; Rosenberg, 1973) was fitted to some snakes. This consisted of a clear perspex tube that was slipped over the head of the snake and sealed to its neck. The anterior end of the chamber had two valved openings. One led to an air pressure transducer, the other was closeable and led to atmosphere. Pressure fluctuations recorded from the closed Kopfkappe thus reflected the ratio of the actual tidal volume of the snake to the volume of the (closed) Kopfkappe itself.

The sensing elements, paired Fenwall GC32L8 bead thermistors, of a bidirectional flow meter (Hill and Givens, 1969) were placed in a tube the end of which could be positioned over the snake's nostril by means of individually shaped extensions of polyethylene tubing. This configuration was necessary because the thermistors were so sensitive that their response to convection currents otherwise provided a very high noise level. The flow meter output gave positive and negative deflections from the baseline values reflecting exhalation and inhalation via the nostrils. The time constant for full-scale deflections of the flow meter was approximately $0.05 \mathrm{sec}$.

A mercury strain gauge around the trunk indicated body wall movements. These were monitored in parallel with pressure fluctuations and air flow (fig. 1). All leads were long enough to permit free movement of the animals within a 20-gal aquarium.

\section{Results}

Experiments involved the placement of the Kopfkappe on a ball python and a boa constrictor. When the Kopfkappe was closed the pressures measured in the trachea 


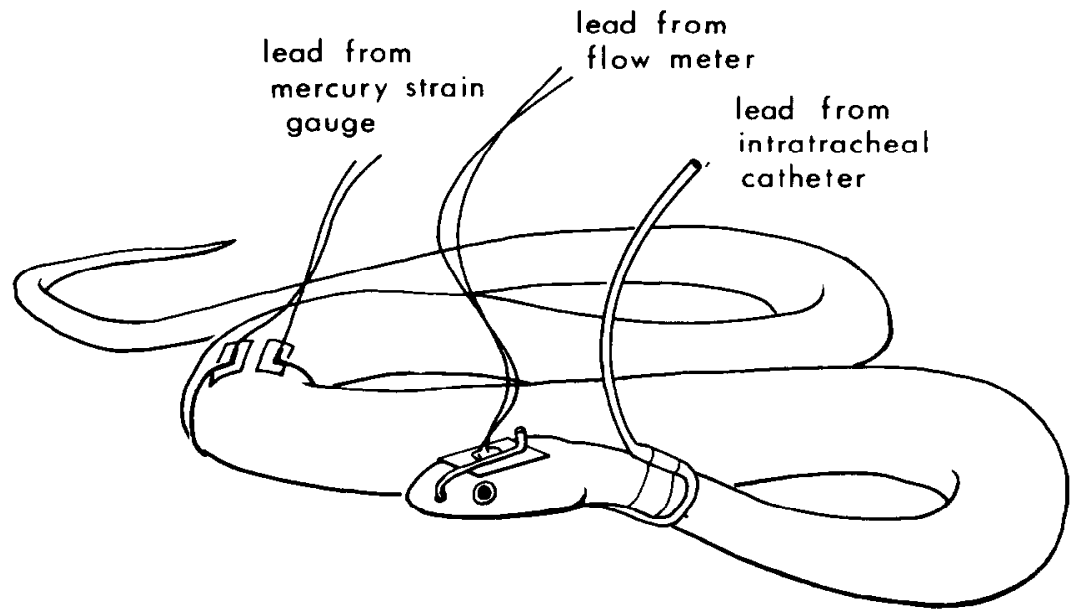

Fig. 1. Arrangement of the recording instrumentation used in these studies. The intratracheal catheter is connected to an external differential pressure transducer. The flow meter monitors air flow at one nostril. A mercury strain gauge monitors changes in the circumference of the snake's trunk. All leads were long enough to allow free movement (and were connected only when the animal was resting).

during exhalation rose sharply. Furthermore, they continued to increase for each of the next five breaths while the negative inhalatory pressures decreased equivalently (fig. 2). The breathing rate increased and the duration of the interbreath intervals decreased. Furthermore, the strain gauge indicated a decrease of costal excursions
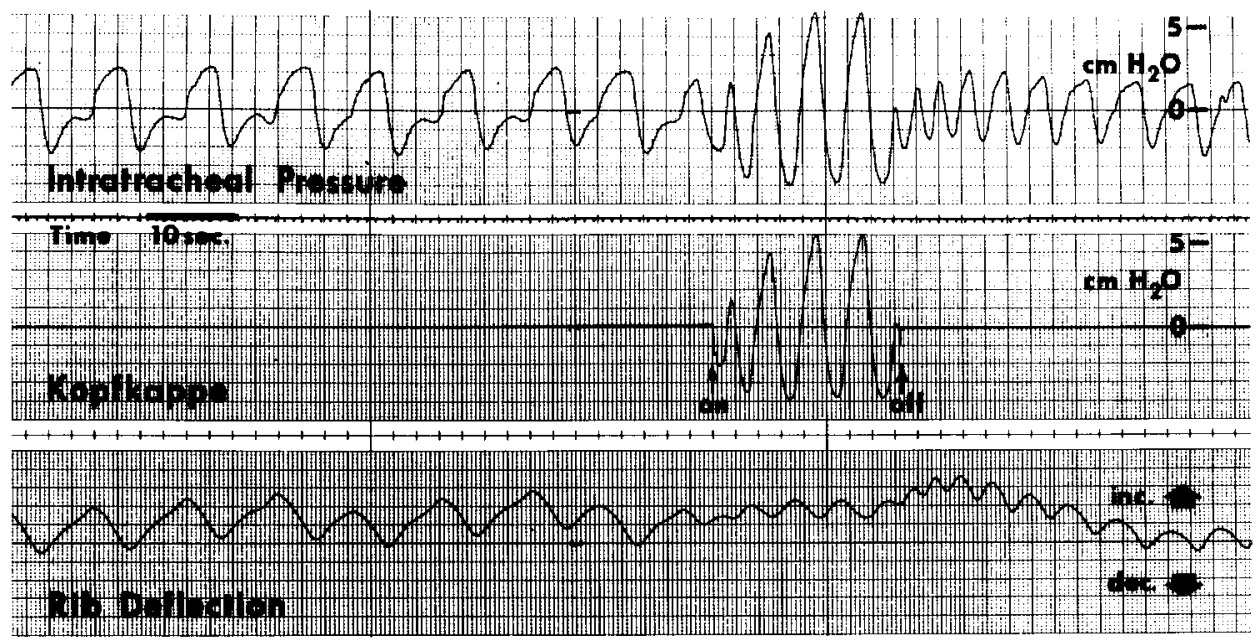

Fig. 2. Boa constrictor. Chart record showing the effect of closing a Kopfkappe on a ventilating snake. Top trace: intratracheal pressure. Middle trace: Kopfkappe pressure. Bottom trace: circumference of trunk (mercury gauge). The arrows indicate when the Kopfkappe was closed off from and opened to atmosphere. See text for details. 
suggesting that tidal flow values were less though the pulmonary pressure fluctuations were greater. Apparently the glottis remained open almost continuously as any shift of the ribs (due to motion of the snake or postventilatory adjustment) produced further pressure changes in the Kopfkappe. When the Kopfkappe was opened the python returned to the previous pressure regime within one breath; however, the boa constrictor breathed more rapidly and shallowly and only gradually $(2-5 \mathrm{~min})$ returned to the previous regime.

Flow patterns were then tested with the Kopfkappe open or in its absence in the other three specimens as well. These results (fig. 3) clearly show the flow to be diphasic. On the other hand the animal may or may not exhibit a rise in tracheal pressure prior to glottal opening and the onset of flow. The moment of glottal opening is generally apparent by a coincident change in the intratracheal pressure or in its rate of change. Reversal from outflow to inflow coincides exactly with the drop of intratracheal pressure below atmospheric (documenting the rapid response of the flow meter), but follows the shift in the deflection curve of the ribs. The maximum inward

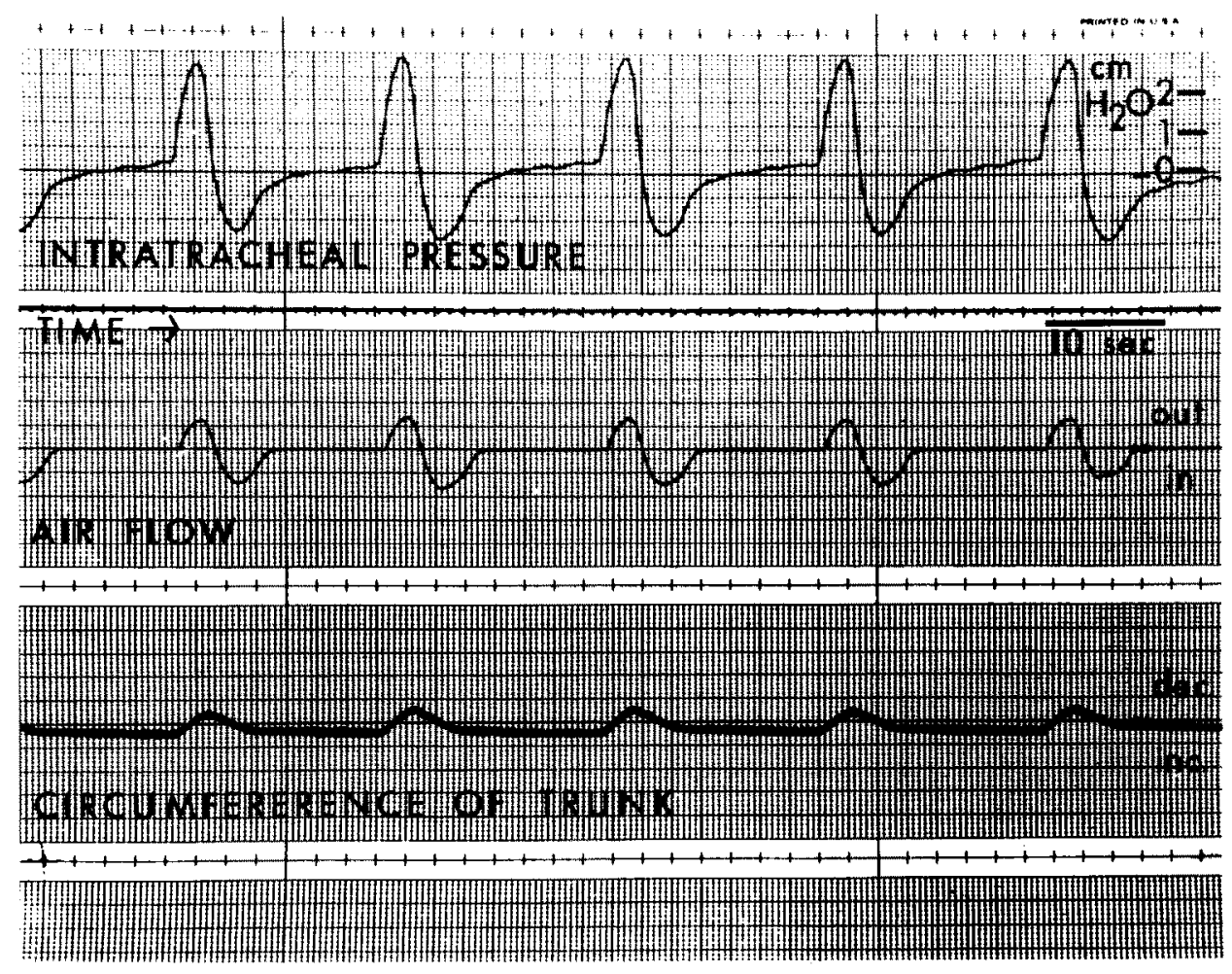

Fig. 3. Bna constrictor. Chart record of the outputs of the instruments shown in fig. 1 during ventilation in an unrestrained, quiescent but excited specimen. Top trace: intratracheal pressure. Middle trace: airflow at nostril. Bottom trace: circumference of trunk (mercury gauge). See text for details. 
position of the ribs slightly precedes the sharp shift of tracheal pressure from peak exhalation to peak inhalation. The position of the ribs (as indicated by the strain gauge) appears to return to resting value before flow terminates. However, flow stops slightly before the intratracheal pressure returns to atmospheric. The pressure then may rise sharply or gradually through the apneic period. Even though the pressure curve may show some irregularities, produced by movements of the snake, these are not reflected as flow events.

\section{Discussion}

The flow records support unequivocally the view that in normally breathing snakes flow is biphasic though ventilation is often accompanied by triphasic or quadriphasic rib movements and pressure changes. Rosenberg's (1973) argument for triphasic flow was based on Kopfkappe experiments and presumably incorporates an artifact. Normally the snake exhales and then inhales. Following inhalation the glottis closes and there is no flow during the prolonged 'apneic' interval (during which much gas is presumably exchanged) in spite of various gradual intratracheal ( intrapulmonary) pressure changes. A second exhalatory phase after inhalation would primarily discharge fresh gas (which required work for its initial inhalation) without significant benefit to the reptile. The present report confirms the argument (Gans, 1970, and earlier authors starting with Bolaert, 1941) that ventilation of resting unrestrained reptiles (turtles, crocodilians and now snakes) involves biphasic flow.

The Kopfkappe or rebreathing chamber has classically been used to obtain samples of gas for analysis during ventilation of various animals (Randall et al., 1944; Templeton and Dawson, 1963; Dmi'el, 1972; Rosenberg, 1973). The results of the present report demonstrate a drastic modification of intratracheal pressure cycles with closure of a Kopfkappe and suggest that this device induces artifacts in ventilatory flow and that it may cause overestimates of metabolism based on gas composition analysis.

The changes in the amplitude of intratracheal pressure fluctuations when the Kopfkappe is closed would seem to indicate that the pressure gradient thereby produced (up to only $6 \mathrm{~cm} \mathrm{H}_{2} \mathrm{O}$ in these experiments) induces a dramatic shift in the ventilatory pattern. This shift may involve proprioreceptive feedback or a response to increased $\mathrm{CO}_{2}$-loading or both (Gatz et al., 1975), although the rapidity of the change of the ventilatory pattern suggests the former. Clearly the volumetric changes in the lung decrease, as indicated by the strain gauge monitoring rib excursion, while intrapulmonary pressure fluctuations increase. This observation suggests that in these animals pulmonary mechanoreceptors (sensitive to stretch rather than pressure) feed back to the areas of the CNS involved in ventilation in a manner analogous to the Herring-Breuer reflex seen in mammals.

These results reconfirm that the use of the Kopfkappe has significant implications in studies of ventilation and respiration (see Saalfeld, 1934, for earlier analysis of 
possible artifacts associated with its use). This device would not only generate artifacts if completely closed, but even a partially closed one should raise intrapulmonary pressure, promote rebreathing and increase ventilatory work. Some investigators, aware of these difficulties, have either connected the closed mask to large volumes relative to the tidal volume of the animal under investigation and recorded small pressure fluctuations from it (e.g. Templeton and Dawson, 1963), or insured that at tidal flow values, resistance of the flow-through mask was low (e.g. Standaert and Johansen, 1974). It is unclear what effect one would obtain when connecting an open Kopfkappe to an aspirating circuit which actively pulls air past the face, but the possibility exists that experimental animals may still be facing significantly unnatural pressures under such circumstances.

\section{Acknowledgements}

We thank Mr. Keith Smith for his careful work in building the flow meter, Dr. C. Carey for comments on the manuscript, and acknowledge NSF BMS 7101380 for supporting this work.

\section{References}

Dmi'el, R. (1972). Effect of activity and temperature on metabolism and water loss in snakes. Am. J. Physiol. 223: 510-516.

Gans, C. and G. M. Hughes (1967). The mechanism of lung ventilation in the tortoise, Testudo graeca Linné. J. Exp. Biol. 47: 1-20.

Gans, C. (1970). Strategy and sequence in the evolution of the external gas exchangers of ectothermal vertebrates. Forma Functio 3: 81-104.

Gans, C. and B. Clark (1976). Studies on ventilation of Caiman crocodilus (Crocodilia: Reptilia). Respir. Physiol. 26: 285-301.

Gatz, R. N., M. R. Fedde and E. C. Crawford, Jr. (1975). Lizard lungs: $\mathrm{CO}_{2}$-sensitive receptors in Tupinambis nigropunctatus. Experientia $31: 455-456$.

Gaunt, A. S. and C. Gans (1969). Mechanics of respiration in the snapping turtle, Chelydra serpentina (Linné). J. Morphol. 128: 195-228.

Hill, M. and R. B. Givens (1969). Air to ground thermal sensor. Flying Models (Rajl. Publ., Sparta, Ill.), (384 March) pp. $20-22,26,39 ; 41-43,50$.

Randall, W. C., D. E. Stullken and W. A. Hiestand (1944). Respiration of reptiles as influenced by the composition of the inspired air. Copeia 1944: 136-144.

Rosenberg, H. I, (1973). Functional anatomy of pulmonary ventilation in the garter snake, Thamnophis elegans. J. Morphol. 140: 171-184.

Saalfeld, E. von (1934). Die Mechanik der Atmung bei Uromastix (Lacertilia). Pflugers Arch. Gesamte Physiol. 233: $431-438$.

Standaert, T. and K. Johansen (1974). Cutaneous gas exchange in snakes. J. Comp. Physiol. 89: 313-320.

Templeton, J. and W. R. Dawson (1963). Respiration in the lizard, Crotaphytus collaris. Physiol. Zool. 36: $104-121$.

Wood, S. C. and C. J. M. Lenfant (1976). Respiration: mechanics, control and gas exchange. In: Biology of the Reptilia, Vol. 5, edited by C. Gans and W. R. Dawson. London, Academic Press. 